\title{
Pharmacist characteristics, medication use perceptions, and professional satisfaction: a first national survey in the state of Qatar
}

\author{
Maguy Saffouh El Hajj' \\ Nadir Kheir' \\ Manal Zaidan² \\ Peter J Jewesson' \\ 'College of Pharmacy, Qatar \\ University, Doha, Qatar; \\ 2Pharmacy Department, Al Amal \\ Cancer Centre, Doha, Qatar
}

Correspondence: Peter J Jewesson College of Pharmacy, Qatar University, Doha 27 I3, Qatar

$\mathrm{Tel}+97444035553$

Fax +974 4403555 I

Email pji@qu.edu.qa
This article was published in the following Dove Press journal:

Journal of Healthcare Leadership

9 February 20II

Number of times this article has been viewed

\begin{abstract}
Purpose: To characterize the professional demographics, opinions about the medication use process, perceived public satisfaction with pharmacy services, and professional satisfaction of pharmacists practicing in the state of Qatar.
\end{abstract}

Materials and methods: The study was designed as a hypothesis-generating, online, anonymous, opinion survey of practicing pharmacists in Qatar.

Results: Two hundred and sixty-four survey accesses were recorded during the 6-week study period, and 250 surveys containing responses to one or more questions were included in the analysis. Eighty-four percent of respondents reported graduating at least 5 years prior to the survey, and $86 \%$ held a baccalaureate degree in pharmacy as their highest degree. The most common source of the highest degree was one of five countries (Egypt, Jordan, India, Sudan, or Pakistan). Forty-five percent of respondents were working in a hospital setting, and 33\% were in a community pharmacy. The lowest incidence of agreement across the 10 drug procurement and distribution process statements was observed for the adequacy of medication supplies statements (33\% of all respondents). The highest incidence of agreement across the eight medication use process statements was for the statement pertaining to infrequent dispensing errors $(68 \%)$, and the lowest incidence of agreement was observed for the statement pertaining to the adequacy of patient monitoring (30\%). The pharmacist was chosen as the best candidate to resolve perceived unmet medication needs for four of eight statements, whereas physicians were most frequently chosen for three of the four remaining statements. Respondents' perceptions regarding patient satisfaction with the different elements of the medication use process revealed that the lowest incidence of agreement pertained to patients' satisfaction with the waiting time required to obtain their medications (35\%). Forty percent of all respondents rated themselves as professionally dissatisfied. Improvements to their professional role, greater opportunities for professional development, and enhancements in human resource-related conditions were identified as potential remedies to this situation.

Conclusion: This study represents the first known attempt to formally solicit the opinions of pharmacists in Qatar. The study results have provided valuable information regarding the demographic characteristics, pharmacist perceptions about the medication use process, and professional satisfaction of practicing pharmacists in the country. This information is being utilized to guide workforce planning, to help identify potential shortcomings in the health care system, and to better understand continuing education and professional satisfaction needs of Qatar's pharmacy practitioners. We encourage other countries to conduct similar surveys in order to better understand the characteristics, perceptions, and needs of their health care workers.

Keywords: pharmacist, characteristics, medication use, perceptions, professional satisfaction 


\section{Introduction}

Health care systems in most countries are under increasing pressure to deliver better services to more people for less cost. Improvement of health care services requires a clear understanding of the characteristics of the health care workforce as well as the conditions of the current health care system. As recently described by Hawthorne and Anderson, the provision of an adequate health care workforce is now considered one of the most pressing global human resource issues worldwide. ${ }^{1}$ To recruit and retain health care workers, attention to the professional satisfaction of these workers is essential. Professional satisfaction is positively associated with roles and responsibilities, interdisciplinary relationships, remuneration packages, and other societal factors such as public recognition of the discipline. ${ }^{1-3}$

The health care system in any country is dependent, in part, on the cost-effective use of medications for the purpose of improving the quality of life of its citizens. It is now well recognized that pharmacists play a major role in ensuring that medications are properly used to achieve this purpose and to control the increasing costs associated with their use. Pharmacists practice in both community and institutional settings and are often considered the most accessible health care workers of the overall medical team. ${ }^{4}$ Accordingly, the opinions of this particular health care worker group about the medication use process may help us to better understand the health care system as a whole. As described by Law et al, developing a better understanding of the perceptions about medication use can complement other efforts aimed at health care system improvements. ${ }^{5}$

Qatar is a small Arabic country located in the Gulf Region of the Middle East. As a result of the discovery of oil and gas, the country has changed from a relatively poor British protectorate to an independent and wealthy state. Qatar has grown from a population of approximately 22,000 people at the turn of the 20th century to over 1.6 million people. Over $80 \%$ of the residents of Qatar are expatriates, drawn to the country by the economic and professional opportunities associated with its growth. ${ }^{6}$ One sector of the country that is also seeing tremendous change is the health care sector. Qatar has a public health care system that is primarily staffed by health care professionals trained outside Qatar. Qatar wishes to increase the involvement of its residents (both Qatari and non-Qatari) in the delivery of health care in the country. To support the training of domestic graduates, the country now hosts satellite campuses of the Weill Cornell Medical College (US based) and the University of Calgary - Qatar (Canada based) nursing school, and, most recently, the College of Pharmacy was established at the national Qatar University.

Qatar currently relies entirely on internationally trained pharmacists. ${ }^{7}$ For the purposes of workforce planning and to assess the health care delivery system from the perspective of pharmacists in the country, the Supreme Council of Health recognized the need to better understand the professional characteristics of the existing health care workforce and to seek input from this workforce regarding the quality of the medication use process in the country. A review of agency records and the indexed English literature revealed that no information has been published in the English literature on this important subject.

\section{Aims of the study}

We initiated a nationwide survey to characterize the professional demographics, opinions about the medication use process, perceived public satisfaction with pharmacy services, and professional satisfaction of pharmacists practicing in the state of Qatar.

\section{Material and methods Study design}

The study was designed as an anonymous opinion survey of a select health provider group within a Middle East country.

\section{Participants}

The eligible study participants were degree-prepared pharmacists from the various health system and community pharmacy practice settings within the state of Qatar.

\section{Assessment tool}

A survey instrument was developed to solicit opinions from the study participants (Appendix A). The survey instrument was Web based and employed a commercially available software. ${ }^{8,9}$ Web-based surveys are comparatively inexpensive, rapidly distributed, avoid transcription and survey alteration issues, and allow anonymity in addition to fast and efficient data collection and analysis. Response rates for Web-based surveys are similar to paper-based surveys. ${ }^{10}$

The survey contained 16 closed-ended and open-ended questions that could be completed within 15 minutes. The survey was designed by the investigators and was based in part on a review of the literature to identify any existing published and validated surveys. The general principles of good survey design were followed. ${ }^{11-13}$ The survey contained five primary sections: 1) respondent demographics and 
practice characteristics, 2) drug procurement and distribution processes, 3) medication use process, 4) public perception and professional satisfaction, and 5) general respondent comments. The medication use process itself can be divided into at least nine sequential components, and these were included in the survey. ${ }^{5}$ A 5-point Likert scale was used to determine the degree of agreement with statements within the relevant sections. Multiple-choice responses and closed- and openended questions were used for the balance of the survey.

The survey was tested for face validity (question clarity, understandability by both English first and second language respondents, and time to completion) by a small group of volunteer pharmacists, and refinements were made before distribution to the intended sample group.

\section{Survey implementation}

The survey was opened at a Qatar University pharmacy program stakeholder meeting on December 4, 2007 and closed on January 15, 2008. Initial online surveys were completed on site by attendees using laptop stations arranged in one of the meeting rooms. Immediately following the meeting, potential respondents were contacted by email, telephone, or fax to solicit their participation. Key personnel in each practice setting were identified and requested to assist the investigators by promoting the participation of their colleagues.

A selection of other methods was used in an attempt to enhance response rates, including: 1) ensuring that the survey was user-friendly, 2) ensuring anonymity and uncensored responses from our neutral academic unit, 3) the use of several contact methods (meeting, telephone, fax, email, newspaper articles) to solicit participation, 4) ensuring timely respondent access to survey results, and 5) promoting the potential benefits of the results to the profession within the country. This was a voluntary anonymous survey. Completion of the survey was considered consent for participation.

\section{Main outcome measures}

The main outcome measures for this study were professional demographics and the extent of agreement to positively phrased statements regarding the medication use process, perceived public satisfaction with pharmacy services, and pharmacist professional satisfaction.

\section{Data analysis}

For the purpose of this study, data analysis was descriptive in nature. To simplify interpretation, degree of agreement with statements was aggregated into three categories (agree, neutral, disagree). Responses were analyzed as a single cohort or with stratification by practice area. Private pharmacists were defined as those pharmacists practicing in a private community pharmacy practice setting. Public clinic pharmacists were those pharmacists practicing in a public clinic (ie, primary health care) setting. Hospital pharmacists included those pharmacists practicing in either a public or a private hospital setting. Other pharmacists were those respondents who did not meet one of those definitions.

Online survey data were downloaded to an Excel spreadsheet and then imported into standard statistical software (Statistical Package for the Social Sciences [SPSS], Version 16; SPSS Inc., Chicago, IL, USA) for descriptive analysis. Responses were collapsed into three general categories (agree, neither agree nor disagree, disagree) to simplify data interpretation. Incomplete surveys were included in the analysis, provided that basic demographic information and a response to the particular question were provided. Accordingly, the denominator (ie, number of respondents) for each response may vary.

The study was one component of an unfunded assessment solicited by the Qatar Supreme Council of Health. To minimize any perception of potential bias and loss of anonymity, the investigators were solely responsible for the administration of the survey, data collection, analysis, and interpretation. The investigators had no vested interest in the specific outcomes of the survey.

\section{Results}

Two hundred and sixty-four online survey accesses were recorded during the 6-week survey collection period. This represents an approximate response rate of $35 \%$ of all pharmacists practicing in Qatar. Fourteen surveys were found to contain no responses or represented duplicate survey attempts and were thus excluded. The remaining 250 surveys contained responses to one or more questions and were included in the analysis. Not all participants provided a response to all survey questions.

\section{Respondent demographics}

The sociodemographic and practice characteristics of participants are summarized in Table 1. Two hundred and seven (84\%) respondents reported graduating at least 5 years prior to the survey. Two hundred and eleven (86\%) respondents possessed a baccalaureate degree only, and the balance reported holding advanced degrees, including MSc, MBA, PharmD, or PhD degrees. The five most common countries awarding the highest degree were Egypt, Jordan, India, 
Table I Pharmacist sociodemographic and practice characteristics

\begin{tabular}{|c|c|}
\hline Characteristic & $\mathbf{N}(\%)$ \\
\hline \multicolumn{2}{|l|}{ Number of years since pharmacy graduation } \\
\hline$<5$ & $39(16)$ \\
\hline $6-10$ & $94(38)$ \\
\hline $11-15$ & $59(24)$ \\
\hline $16-20$ & $18(7)$ \\
\hline$>20$ & $36(15)$ \\
\hline \multicolumn{2}{|l|}{ Highest pharmacy degree } \\
\hline Bachelor of Pharmacy & $211(86)$ \\
\hline Pharm D & $6(3)$ \\
\hline MSc or MPharm & $12(5)$ \\
\hline $\mathrm{PhD}$ & $5(2)$ \\
\hline MBA & $3(1)$ \\
\hline Other & $8(3)$ \\
\hline \multicolumn{2}{|l|}{ Country awarding highest degree } \\
\hline Egypt & $74(3 \mathrm{I})$ \\
\hline Jordan & $46(19)$ \\
\hline India & $36(15)$ \\
\hline Other countries & $37(15)$ \\
\hline Sudan & $21(9)$ \\
\hline Pakistan & $17(7)$ \\
\hline Philippines & $10(4)$ \\
\hline \multicolumn{2}{|l|}{ Pharmacy practice history prior to Qatar } \\
\hline No previous practice & $43(18)$ \\
\hline Egypt & $47(19)$ \\
\hline India & $23(10)$ \\
\hline Sudan & $23(10)$ \\
\hline Jordan & $20(8)$ \\
\hline Other countries & $20(8)$ \\
\hline Saudi Arabia & $12(5)$ \\
\hline More than one Middle Eastern country & II (5) \\
\hline Pakistan & $10(4)$ \\
\hline One Middle Eastern country and Sudan & $10(4)$ \\
\hline One Middle Eastern and one South Asian country & $9(4)$ \\
\hline Philippines & $6(2)$ \\
\hline Syria & $4(2)$ \\
\hline Middle Eastern plus (New Zealand or Canada & $3(1)$ \\
\hline \multicolumn{2}{|l|}{ or a European country) } \\
\hline \multicolumn{2}{|l|}{ Years of practice in Qatar } \\
\hline$<2$ & $42(17)$ \\
\hline $2-5$ & $95(40)$ \\
\hline $6-10$ & $57(24)$ \\
\hline $11--15$ & $19(8)$ \\
\hline$>15$ & $27(\mathrm{II})$ \\
\hline \multicolumn{2}{|l|}{ Current general area of pharmacy practice } \\
\hline Public hospital setting & $104(42)$ \\
\hline Independent community pharmacy & $45(18)$ \\
\hline Chain community pharmacy & $37(15)$ \\
\hline Public clinic & $26(I I)$ \\
\hline Private clinic & $11(4)$ \\
\hline Government & $6(3)$ \\
\hline Private hospital setting & $6(3)$ \\
\hline Academia & $4(2)$ \\
\hline Industry & $3(1)$ \\
\hline Other & $2(1)$ \\
\hline \multicolumn{2}{|l|}{ Current pharmacy practice role } \\
\hline Hospital pharmacist & $104(42)$ \\
\hline Community pharmacist & $77(32)$ \\
\hline Coordinator, manager, or supervisor & $40(16)$ \\
\hline Other & $19(8)$ \\
\hline Director & $5(2)$ \\
\hline
\end{tabular}

Sudan, or Pakistan (194 [81\%] respondents). Nine other countries were also represented in the survey.

One hundred and ninety-eight ( $82 \%)$ respondents reported previous practice experience in at least one other country prior to arrival in Qatar. One hundred and ninety-nine (82\%) respondents reported having practiced for at least 2 years in the country. One hundred and ten $(45 \%)$ pharmacists reported working in a hospital setting, whereas 82 (33\%) were working in a community pharmacy setting, 26 (11\%) practiced in a public clinic, and $11(4 \%)$ were in a private clinic. The remaining 15 (7\%) respondents worked in a governmental, academic, industry, or other setting. Seventy-seven $(32 \%)$ respondents were community pharmacists, and 104 respondents $(42 \%)$ were in the hospital setting. Forty $(16 \%)$ respondents were in managerial positions, and the balance were in other positions.

\section{Perceptions of drug procurement and distribution processes}

Tables 2, 3, and 4 show the extent of agreement with statements regarding drug procurement and distribution. The majority of respondents tended to agree with four statements related to formulary (Table 2). The overall range of agreement across the four statements for this category ranged from $57 \%$ to $65 \%$, with $12 \%-19 \%$ of respondents providing a neutral response. There were some differences in agreement between and across the respondent groups, with a generally higher incidence of agreement with the four statements in the "other" group.

Fewer respondents tended to agree with the three statements related to supplies and regulations, and there was a two-fold range $(33 \%-62 \%)$ in the incidence of positive responses (Table 3 ). The lowest overall incidence of agreement across the 10 drug procurement and distribution process statements (Tables 2, 3, and 4) was observed for the adequacy of medication supplies statement. Only 33\% of all respondents and $17 \%$ of the "private" respondent group agreed with the statement.

Most respondents $(53 \%-63 \%)$ agreed with the three statements pertaining to dispensing (Table 4). The "private" group tended to report the lowest incidence of agreement (32\%-49\%), whereas the "public clinic" group reported the highest percentage of positive responses $(59 \%-86 \%)$ across the statements.

\section{Perceptions of the medication use process}

Table 5 shows the extent of agreement with the eight medication use process statements. Overall, the highest 
Table 2 Pharmacist perceptions of drug procurement and distribution processes (formulary)

\begin{tabular}{|c|c|c|c|c|}
\hline \multirow[t]{2}{*}{ Statement } & \multirow[t]{2}{*}{ Group $^{b}$} & \multicolumn{3}{|l|}{$\mathbf{N}(\%)^{\mathbf{a}}$} \\
\hline & & Agree & Neutral & Disagree \\
\hline The formulary process for selecting medications for & Private & $40(56)$ & $10(14)$ & $21(30)$ \\
\hline \multirow[t]{4}{*}{ sale is adequate } & Public clinic & $13(57)$ & $6(26)$ & $4(17)$ \\
\hline & Hospital & $52(60)$ & $21(24)$ & $14(16)$ \\
\hline & Other & $19(76)$ & $2(8)$ & $4(16)$ \\
\hline & Total & $124(60)$ & $39(19)$ & $43(21)$ \\
\hline New and beneficial medications are added to the & Private & $39(55)$ & $8(I I)$ & $24(34)$ \\
\hline \multirow[t]{4}{*}{ formulary in a timely manner } & Public clinic & $15(66)$ & $4(17)$ & $4(17)$ \\
\hline & Hospital & $61(70)$ & $10(1 \mathrm{I})$ & $17(19)$ \\
\hline & Other & 19 (79) & $3(13)$ & $2(8)$ \\
\hline & Total & $134(65)$ & $25(12)$ & $47(23)$ \\
\hline The range and types of prescription medications & Private & $37(5 \mathrm{I})$ & $7(9)$ & $29(40)$ \\
\hline \multirow[t]{4}{*}{ available for sale are adequate } & Public clinic & $14(64)$ & $6(27)$ & $2(9)$ \\
\hline & Hospital & $47(57)$ & $22(27)$ & $13(16)$ \\
\hline & Other & $17(68)$ & $\mathrm{I}(4)$ & $7(28)$ \\
\hline & Total & $115(57)$ & $36(18)$ & $51(25)$ \\
\hline The range and types of over-the-counter & Private & $36(49)$ & $8(I I)$ & $29(40)$ \\
\hline medications available for sale (including those & Public clinic & $18(78)$ & $3(13)$ & $2(9)$ \\
\hline requiring a prescription in the hospital) are & Hospital & $46(57)$ & $18(22)$ & $17(21)$ \\
\hline \multirow[t]{2}{*}{ adequate } & Other & $17(74)$ & I (4) & $5(22)$ \\
\hline & Total & II7 (59) & $30(15)$ & $53(26)$ \\
\hline
\end{tabular}

Notes: aResponses have been collapsed into a 3-point scale; neutral implies "neither disagree nor disagree"; bPrivate: pharmacists practicing in private community pharmacies; public clinic: pharmacists practicing in public clinic pharmacies; hospital: pharmacists practicing in public and private hospital pharmacies; other: pharmacists in other government, academic, industry, or undeclared settings.

incidence of agreement was for the statement pertaining to infrequent dispensing errors (68\%), and the lowest incidence of agreement was observed for the statement pertaining to the adequacy of patient monitoring (30\%). There was close agreement across the respondents in terms of within-group agreement ranking, with two exceptions. The "other" group had the highest incidence of agreement with the statement regarding dispensing errors (57\%), and the "public clinic" group had the lowest incidence of agreement with the statement regarding the appropriateness of physicians' decisions to use medications ( $31 \%)$.

Table 6 shows the extent of agreement with statements about the best candidate(s) to address any perceived unmet medication needs. The pharmacist was chosen as the best

Table 3 Pharmacist perceptions of drug procurement and distribution processes (supplies and regulations)

\begin{tabular}{|c|c|c|c|c|}
\hline \multirow[t]{2}{*}{ Statement } & \multirow[t]{2}{*}{ Group $^{b}$} & \multicolumn{3}{|l|}{$\mathbf{N}(\%)^{a}$} \\
\hline & & Agree & Neutral & Disagree \\
\hline \multirow{5}{*}{$\begin{array}{l}\text { The stock of medication supplies is adequate and } \\
\text { shortages are uncommon }\end{array}$} & Private & $13(17)$ & $8(\mathrm{II})$ & $53(72)$ \\
\hline & Public clinic & $10(44)$ & $4(17)$ & $9(39)$ \\
\hline & Hospital & 33 (37) & $14(16)$ & $41(47)$ \\
\hline & Other & $12(52)$ & $6(26)$ & $5(22)$ \\
\hline & Total & $68(33)$ & 32 (I5) & $108(52)$ \\
\hline \multirow{5}{*}{$\begin{array}{l}\text { The regulatory processes for the procurement } \\
\text { and storage of medications are adequate }\end{array}$} & Private & $44(63)$ & $14(20)$ & $12(17)$ \\
\hline & Public clinic & $12(52)$ & $4(17)$ & $7(3 I)$ \\
\hline & Hospital & $5 I(6 I)$ & $17(20)$ & $16(19)$ \\
\hline & Other & I7 (7I) & $4(17)$ & $3(12)$ \\
\hline & Total & $124(62)$ & 39 (19) & 38 (19) \\
\hline \multirow{5}{*}{$\begin{array}{l}\text { The regulatory processes for the marketing and } \\
\text { pricing of medications are adequate }\end{array}$} & Private & $32(44)$ & $9(13)$ & 31 (43) \\
\hline & Public clinic & $10(46)$ & $8(36)$ & $4(18)$ \\
\hline & Hospital & $35(48)$ & $22(30)$ & $16(22)$ \\
\hline & Other & $16(69)$ & $2(9)$ & $5(22)$ \\
\hline & Total & 93 (49) & $4 I(22)$ & $56(29)$ \\
\hline
\end{tabular}

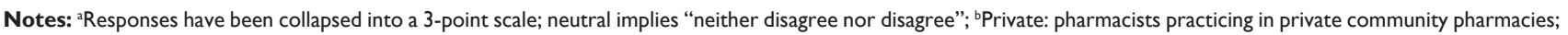
public clinic: pharmacists practicing in public clinic pharmacies; hospital: pharmacists practicing in public and private hospital pharmacies; other: pharmacists in other government, academic, industry, or undeclared settings. 
Table 4 Pharmacist perceptions of drug procurement and distribution processes (dispensing)

\begin{tabular}{|c|c|c|c|c|}
\hline \multirow[t]{2}{*}{ Statement } & \multirow[t]{2}{*}{ Group $^{\mathrm{b}}$} & \multicolumn{3}{|l|}{$\mathbf{N}(\%)^{\mathbf{a}}$} \\
\hline & & Agree & Neutral & Disagree \\
\hline In general, the processes for dispensing medications from & Private & $35(49)$ & $15(2 I)$ & $22(30)$ \\
\hline \multirow[t]{4}{*}{ community pharmacies are adequate } & Public clinic & $13(59)$ & $4(18)$ & $5(23)$ \\
\hline & Hospital & $44(59)$ & $17(23)$ & $13(18)$ \\
\hline & Other & $10(42)$ & 7 (29) & $7(29)$ \\
\hline & Total & $102(53)$ & $43(22)$ & $47(25)$ \\
\hline In general, the processes for distribution of medications & Private & $20(32)$ & $17(28)$ & $25(40)$ \\
\hline from public clinics (eg, primary health care center) & Public clinic & $17(74)$ & $2(9)$ & $3(13)$ \\
\hline \multirow[t]{3}{*}{ pharmacies are adequate } & Hospital & $43(60)$ & $14(19)$ & $15(2 \mid)$ \\
\hline & Other & $14(63)$ & $5(23)$ & $3(14)$ \\
\hline & Total & $94(53)$ & $38(21)$ & $46(26)$ \\
\hline In general, the processes for distribution of medications & Private & $30(46)$ & $14(22)$ & $21(32)$ \\
\hline from public hospital outpatient (eg, HMC) pharmacies & Public clinic & $18(86)$ & $0(0)$ & $3(14)$ \\
\hline \multirow[t]{3}{*}{ are adequate } & Hospital & $54(67)$ & $9(11)$ & $18(22)$ \\
\hline & Other & $15(75)$ & $3(15)$ & $2(10)$ \\
\hline & Total & $117(63)$ & $26(14)$ & $44(23)$ \\
\hline
\end{tabular}

Notes: aResponses have been collapsed into a 3-point scale; neutral implies "neither disagree nor disagree"; ${ }^{\text {bPivate: }}$ pharmacists practicing in private community pharmacies; public clinic: pharmacists practicing in public clinic pharmacies; hospital: pharmacists practicing in public and private hospital pharmacies; other: pharmacists in other government, academic, industry, or undeclared settings.

candidate for four of eight statements (45\%-81\%), whereas physicians were most frequently chosen for three of the four remaining statements $(55 \%-66 \%)$. For three statements (decision to use medications, prescription writing errors, and patient monitoring), respondents tended to select a combination of both pharmacists and physicians. The patient was selected as the best candidate for one category (visit their physician at the right time), whereas managers and government staff were infrequently identified as the best candidate to resolve the unmet medication needs identified.

Using open-ended questions, respondents were also asked to provide general opinions regarding those aspects of the medication use process that they felt were the best, those in need of greatest improvement, and their recommendations for change.

Ninety-two respondents (37\% of total respondents) provided opinions in response to at least one of these two questions regarding those aspects of the medication use process that would be considered the best, and those in greatest need of improvement. More than $70 \%$ of these responses came from pharmacists from the private and hospital sectors. The private sector respondents most commonly identified the medication distribution (eg, drug quality, price, procurement, and dispensing) and the health care providers and institutions as being both the best aspect of the overall medication use process and that in greatest need of improvement. The hospital sector respondents most commonly identified medication availability as the best aspect of the overall process, but they identified medication distribution as the component in greatest need of improvement. Public clinic sector pharmacists identified health care providers and institutions as the best aspect, and distribution as that in greatest need of improvement; however, the overall number of responses from this group was low.

\section{Perceptions of patient satisfaction with the medication use process}

Table 7 shows the extent of agreement with statements regarding the level of patient satisfaction with the different elements of the medication use process. Overall, there was less than $60 \%$ agreement with each of the five statements. The incidence of agreement across statements for the combined subgroups varied from $35 \%$ to $58 \%$ (1.6-fold). The lowest incidence of agreement across the statements pertained to patient satisfaction with the delays to obtain medications, whereas the highest perceived satisfaction was related to quality of medications. Response characteristics between practice groups were relatively similar, with the exception of the private practice and the hospital groups. The private practice group reported the lowest percentage of agreement with statements related to perceived patient satisfaction with the availability (37\%) and cost (9\%) of medications. The hospital group reported the lowest percentage of agreement with the statements pertaining to patient satisfaction with outpatient prescription waiting time (18\%).

\section{Professional satisfaction}

The proportion of professionally satisfied pharmacists was similar to those who reported themselves as being professionally dissatisfied ( $40 \%$ vs $41 \%$ of respondents). 
Table 5 Pharmacist perceptions of medication use process

\begin{tabular}{|c|c|c|c|c|}
\hline \multirow[t]{2}{*}{ Statement } & \multirow[t]{2}{*}{ Group $^{b}$} & \multicolumn{3}{|l|}{$\mathbf{N}(\%)^{a}$} \\
\hline & & Agree & Neutral & Disagree \\
\hline \multirow[t]{5}{*}{ Patients visit their physician at the right time } & Private & $18(26)$ & $15(22)$ & $35(52)$ \\
\hline & Public clinic & $9(39)$ & $5(22)$ & 9 (39) \\
\hline & Hospital & $32(40)$ & $13(16)$ & $35(44)$ \\
\hline & Other & $7(30)$ & $6(26)$ & $10(44)$ \\
\hline & Total & $66(34)$ & $39(20)$ & $89(46)$ \\
\hline The physician's decision to use medications & Private & $35(50)$ & $19(27)$ & $16(23)$ \\
\hline \multirow[t]{4}{*}{ is appropriate } & Public clinic & $7(31)$ & $10(43)$ & $6(26)$ \\
\hline & Hospital & $32(40)$ & $25(31)$ & $23(29)$ \\
\hline & Other & II (48) & $5(22)$ & $7(30)$ \\
\hline & Total & $85(43)$ & $59(30)$ & $52(27)$ \\
\hline Less than $5 \%$ of prescriptions received by & Private & $43(62)$ & $9(13)$ & $17(25)$ \\
\hline \multirow[t]{4}{*}{ pharmacists contain errors } & Public clinic & $8(35)$ & $3(13)$ & $12(52)$ \\
\hline & Hospital & $31(39)$ & $7(9)$ & $42(52)$ \\
\hline & Other & $8(36)$ & $3(14)$ & II (50) \\
\hline & Total & $90(46)$ & $22(12)$ & $82(42)$ \\
\hline Patients get their prescriptions filled & Private & $35(56)$ & $14(22)$ & $14(22)$ \\
\hline \multirow[t]{4}{*}{ in a timely manner } & Public clinic & $15(65)$ & $3(13)$ & $5(22)$ \\
\hline & Hospital & $46(56)$ & $11(13)$ & $26(31)$ \\
\hline & Other & $12(54)$ & $2(9)$ & $8(36)$ \\
\hline & Total & $108(57)$ & $30(15)$ & $53(28)$ \\
\hline \multirow[t]{5}{*}{ Dispensing errors are low } & Private & $51(74)$ & $8(12)$ & $10(15)$ \\
\hline & Public clinic & $15(65)$ & $2(9)$ & $6(26)$ \\
\hline & Hospital & $54(66)$ & $8(10)$ & $20(24)$ \\
\hline & Other & $13(57)$ & $4(17)$ & $6(26)$ \\
\hline & Total & $133(68)$ & $22(11)$ & $42(21)$ \\
\hline Patients receive adequate medication & Private & $31(45)$ & $8(12)$ & $29(43)$ \\
\hline \multirow[t]{4}{*}{ counseling } & Public clinic & II (48) & $0(0)$ & $12(52)$ \\
\hline & Hospital & $29(35)$ & $12(15)$ & $4 \mid(50)$ \\
\hline & Other & $13(54)$ & $5(2 I)$ & $6(25)$ \\
\hline & Total & $84(43)$ & $25(13)$ & $88(44)$ \\
\hline Patients take (or are administered) their & Private & $29(44)$ & $12(18)$ & $25(38)$ \\
\hline \multirow[t]{4}{*}{ medications as directed } & Public clinic & $14(64)$ & $5(23)$ & $3(13)$ \\
\hline & Hospital & $34(44)$ & $25(32)$ & $19(24)$ \\
\hline & Other & $5(22)$ & $9(39)$ & $9(39)$ \\
\hline & Total & $82(43)$ & $51(27)$ & $56(30)$ \\
\hline \multirow[t]{5}{*}{ Patients are monitored appropriately } & Private & $17(27)$ & $17(27)$ & $29(46)$ \\
\hline & Public clinic & II (50) & $5(23)$ & $6(27)$ \\
\hline & Hospital & $25(32)$ & $17(21)$ & $37(47)$ \\
\hline & Other & $4(16)$ & II (46) & $9(38)$ \\
\hline & Total & $57(30)$ & $50(27)$ & $81(43)$ \\
\hline
\end{tabular}

Notes: aResponses have been collapsed into a 3-point scale; neutral implies "neither disagree nor disagree”; 'Private: pharmacists practicing in private community pharmacies; public clinic: pharmacists practicing in public clinic pharmacies; hospital: pharmacists practicing in public and private hospital pharmacies; other: pharmacists in other government, academic, industry, or undeclared settings.

More pharmacists in the public clinic environment $(58 \%)$ reported themselves to be professionally satisfied than the other groups, and hospital pharmacists had the lowest proportion (30\%) of professionally satisfied respondents.

Seventy-eight respondents offered suggestions to improve their level of professional satisfaction. Forty-five respondents (58\%) identified improvements to the professional role of the pharmacist and greater opportunities for professional development. Thirty-six respondents $(46 \%)$ recommended enhancements in human resource-related conditions (eg, adequate staffing, reduced workload, and better compensation). The remaining responses (each accounting for less than $10 \%$ of the total) involved recommendations for advancements in the medication distribution process, pharmacists' professional activities, and changes to drug regulation.

\section{Discussion}

This study represents the first published report to characterize the professional demographics, medication use process 
Table 6 Pharmacist perceptions of best candidate(s) to resolve unmet medication needs

\begin{tabular}{|c|c|c|c|c|c|c|c|}
\hline \multirow[t]{2}{*}{ Statement } & \multicolumn{7}{|l|}{$\mathbf{N}(\%)$} \\
\hline & Pharmacist & Physician & Nurse & Patient & Manager & Government & Unknown \\
\hline $\begin{array}{l}\text { Patients visit their physician at the } \\
\text { right time }\end{array}$ & $18(17)$ & $20(19)$ & 7 (7) & $46(44)$ & $19(18)$ & $19(18)$ & $6(6)$ \\
\hline $\begin{array}{l}\text { The physician's decision to use } \\
\text { medications is appropriate }\end{array}$ & $40(46)$ & $50(57)$ & I (I) & $5(6)$ & I (I) & $6(7)$ & $4(5)$ \\
\hline $\begin{array}{l}\text { Less than } 5 \% \text { of prescriptions received } \\
\text { by pharmacists contain errors }\end{array}$ & $4 \mid(42)$ & $65(66)$ & $4(4)$ & $2(2)$ & $9(9)$ & $10(10)$ & $4(4)$ \\
\hline $\begin{array}{l}\text { Patients get their prescriptions filled } \\
\text { in a timely manner }\end{array}$ & $35(45)$ & $15(19)$ & $5(6)$ & $19(24)$ & $19(24)$ & $8(10)$ & $6(8)$ \\
\hline Dispensing errors are low & $60(78)$ & $17(22)$ & $6(8)$ & $6(8)$ & $7(9)$ & $5(6)$ & $5(6)$ \\
\hline $\begin{array}{l}\text { Patients receive adequate medication } \\
\text { counseling }\end{array}$ & $81(8 I)$ & $27(27)$ & II (II) & $5(5)$ & $17(17)$ & $12(12)$ & $3(3)$ \\
\hline $\begin{array}{l}\text { Patients take (or are administered) } \\
\text { their medications as directed }\end{array}$ & $44(55)$ & $16(20)$ & $17(2 \mid)$ & $35(44)$ & $2(2)$ & $5(6)$ & $3(4)$ \\
\hline Patients are monitored appropriately & $42(43)$ & $54(55)$ & $26(26)$ & $13(13)$ & $9(9)$ & $12(12)$ & $8(8)$ \\
\hline Average (range) & $45(|7-8|)$ & $33(19-66)$ & $10(I-26)$ & $16(2-44)$ & $10(I-24)$ & $10(6-18)$ & $5(3-8)$ \\
\hline
\end{tabular}

perceptions, perceived public satisfaction with pharmacy services, and professional satisfaction of pharmacists practicing in the state of Qatar.

The study reveals that the majority of pharmacists practicing in the country are educated in one of five countries located within the overall region. We recently published a regional assessment of pharmacy education and practice and found that Egypt was the greatest contributor of baccalaureate pharmacy graduates within the 12 Arabic-speaking countries assessed. ${ }^{7}$ In the present study, we found that Egyptian-trained BSc (Pharm) graduates are also the most prevalent pharmacy practitioners in Qatar, followed by Jordan, India, Sudan, and

Table 7 Pharmacist perceptions about patient satisfaction with the medication use process

\begin{tabular}{|c|c|c|c|c|}
\hline \multirow[t]{2}{*}{ Statement } & \multirow[t]{2}{*}{ Group $^{b}$} & \multicolumn{3}{|l|}{$\mathbf{N}(\%)^{\mathrm{a}}$} \\
\hline & & Agree & Neutral & Disagree \\
\hline \multirow{5}{*}{$\begin{array}{l}\text { Patients are usually satisfied with the } \\
\text { availability of supplies of their medication }\end{array}$} & Private & $25(37)$ & $9(14)$ & $33(49)$ \\
\hline & Public clinic & $12(60)$ & $2(10)$ & $6(30)$ \\
\hline & Hospital & $45(58)$ & $16(20)$ & $17(22)$ \\
\hline & Other & $15(60)$ & $5(20)$ & $5(20)$ \\
\hline & Total & $97(5 \mathrm{I})$ & $32(17)$ & $61(32)$ \\
\hline \multirow{5}{*}{$\begin{array}{l}\text { Patients are usually satisfied with the quality } \\
\text { of their medications }\end{array}$} & Private & $40(60)$ & $15(22)$ & $12(18)$ \\
\hline & Public clinic & $10(50)$ & $3(15)$ & $7(35)$ \\
\hline & Hospital & $45(58)$ & $18(23)$ & $15(19)$ \\
\hline & Other & $13(52)$ & $5(20)$ & $7(28)$ \\
\hline & Total & $108(58)$ & $4 I(2 I)$ & $4 \mid(2 I)$ \\
\hline \multirow{5}{*}{$\begin{array}{l}\text { Patients are usually satisfied with the waiting } \\
\text { time required to obtain their medications }{ }^{c}\end{array}$} & Private & 33 (49) & $11(17)$ & $23(34)$ \\
\hline & Public clinic & $9(45)$ & $4(20)$ & 7 (35) \\
\hline & Hospital & $14(18)$ & $6(8)$ & $58(74)$ \\
\hline & Other & $10(40)$ & $4(16)$ & II (44) \\
\hline & Total & $66(35)$ & $25(13)$ & $99(52)$ \\
\hline \multirow{5}{*}{$\begin{array}{l}\text { Patients are usually satisfied with the cost } \\
\text { of their medications }\end{array}$} & Private & $6(9)$ & $11(16)$ & $50(75)$ \\
\hline & Public clinic & $14(70)$ & $3(15)$ & $3(15)$ \\
\hline & Hospital & $54(69)$ & 7 (9) & $17(22)$ \\
\hline & Other & $10(38)$ & $8(31)$ & $8(31)$ \\
\hline & Total & $84(44)$ & $29(15)$ & $78(4 I)$ \\
\hline \multirow{5}{*}{$\begin{array}{l}\text { Patients are usually satisfied with the quality } \\
\text { of pharmacy services provided to them }\end{array}$} & Private & $42(63)$ & $17(25)$ & $8(12)$ \\
\hline & Public clinic & $12(60)$ & $2(10)$ & $6(30)$ \\
\hline & Hospital & $32(4 I)$ & $26(33)$ & $20(26)$ \\
\hline & Other & $13(52)$ & $6(24)$ & $6(24)$ \\
\hline & Total & $99(52)$ & 5I (27) & $40(2 \mathrm{I})$ \\
\hline
\end{tabular}

Notes: aResponses have been collapsed into a 3-point scale; neutral implies "neither disagree nor disagree"; ${ }^{\text {PPivate: }}$ pharmacists practicing in private community pharmacies; public clinic: pharmacists practicing in public clinic pharmacies; hospital: pharmacists practicing in public and private hospital pharmacies; other: pharmacists in other government, academic, industry, or undeclared settings. 'Outpatient department prescriptions in the hospital setting. 
Pakistan. Accordingly, the level of practice of pharmacy in Qatar is heavily dependent on the training provided in the pharmacy programs within these countries. As the newly Canadian-accredited pharmacy degree program in Qatar begins to graduate domestically trained pharmacists, dependence on international pharmacists will be reduced, as well as the heterogeneity of training background.

Most respondents to the survey had practiced for at least 5 years in another country before moving to Qatar, and most had 2 or more years of practical experience in the country. Accordingly, the respondents were considered to have had sufficient experience to develop informed opinions about conditions in the country. According to our results, the majority of these pharmacists believed that the formulary process in Qatar is adequate and that new drug products are being added to the formulary in a timely manner. Pharmacists were also of the impression that the range and types of prescription and over-the-counter medications available for sale are adequate to meet local needs. That said, fewer pharmacists were of the opinion that medication supplies are adequate and that shortages are uncommon in the country. Qatar currently has no local pharmaceutical industry and thus is reliant on importation of all medications. As medication supplies compete with shipments for other goods in this rapidly developing country, delays can be expected.

Most pharmacists reported that the processes for drug procurement and distribution in the country are adequate. They appeared to be satisfied with the processes associated with dispensing of medications in the retail setting, public clinics, and public hospital outpatient pharmacies, and felt that the regulatory processes for the procurement, storage, marketing, and pricing of medications are also acceptable. Considering that the rules and regulations governing the practice of pharmacy in Qatar generally resemble those of the countries of origin for the respondents, this finding was not unexpected.

When asked for opinions regarding the medication use process in Qatar, most respondents felt that dispensing errors were infrequent, and fewer believed that patient monitoring was inadequate. Although Law et al reported a similar finding for dispensing errors, a higher proportion of pharmacists in the previous study believed that patient monitoring was satisfactory. ${ }^{5}$ This impression is likely associated with the lack of patient medication profiles in the community sector in the country and with the lack of integrated electronic health records in the hospital sector. In the absence of these records, pharmacists and physicians are unable to adequately monitor medication use to ensure that desired outcomes are being achieved.
Finally, this study also revealed that pharmacists perceive that the public is generally unsatisfied with current medication use process conditions. Not unexpectedly, the lowest perceived patient satisfaction regarding medication availability and cost was in the private practice sector. Patient satisfaction regarding waiting times was lowest in the hospital sector where outpatient volumes are very high in the country. Although quality of medications received the highest perceived patient satisfaction rating, it did not exceed $60 \%$ for any one group. This suggests that patients may have concerns about the medication source and standards in the country. This finding may warrant attention by the drug regulation agency, at least in terms of providing the public with information pertaining to the drug product approval process in Qatar and designing strategies to further improve the current medication use system. Finally, only half of pharmacists believed that patients were satisfied with the level of pharmacy services provided to them. Although further investigation is necessary to better understand the pharmacist impressions of public satisfaction, we interpret these findings to mean that pharmacists believe that they are capable of providing more services to patients than current conditions permit.

According to our study, pharmacists in the country also perceive that they are the most appropriate health care professional to resolve the majority of unmet needs in the medication process. This is also similar to responses reported by Law et al, and we consider this to be a critical finding of the current study. ${ }^{5}$ Accountability for medication outcomes is a key to the advancement of the pharmacy profession in any country, and those in Qatar wish to emulate a national vision for pharmacy such as that recently adopted by Canada. ${ }^{14}$ We were encouraged to observe that respondents commonly identified that medication use improvement would best be achieved by improving pharmacist professional skills and through the enhancement of the role of pharmacists in the delivery of health care in Qatar.

We found that 4 out of every 10 pharmacists in the country considered themselves to be professionally dissatisfied, and this was highest in the hospital sector. When compared with some other countries, the level of professional satisfaction appears to be lower. ${ }^{15-17}$ Consistent with recommendations toward improving the medication use process, pharmacists pointed to a lack of professional recognition and opportunities for advancement as the primary reasons for this professional dissatisfaction. Human resource issues, including workload and compensation, also appeared to be responsible for dissatisfaction in the country. These results deserve attention, considering that pharmacist professional dissatisfaction has 
been linked to employment attrition, dispensing errors, and potential negative health outcomes. ${ }^{18,19}$

Although Arabic is the first language in Qatar, it is also apparent from this study that a Web-based English language survey is an effective and inexpensive tool for the purpose of obtaining input from the practicing pharmacist population in the country. Accordingly, this instrument will be used for future surveys of pharmacists in the country.

\section{Limitations}

As this was a voluntary survey, the responses may have contained self-reporting data inaccuracies resulting from intentional deception, poor memory, or misunderstanding of the question. The survey was English based and online only. This limited the survey to those pharmacists who had access to an online computer and prohibited pharmacists who were not conversant in the English language from participating. Finally, the response rate of about $30 \%$ of all practicing pharmacists means that we must be cautious about the generalizability of the study findings.

\section{Conclusion}

This study represents the first known attempt to characterize the professional demographics of pharmacists in Qatar, as well as to solicit the opinions of practicing pharmacists regarding issues of the medication use process, perceived patient satisfaction with pharmacy services, and professional satisfaction. This information has proven valuable to better understand the current pharmacy workforce and medication use process in the country, and is being used to plan for future improvements to the overall health care system. We encourage other countries to conduct similar surveys in order to better understand the needs and perceptions of their health care workers.

\section{Acknowledgments}

This research received no grant from any funding agency in the public, commercial, or not for profit sectors. Any costs were borne by Qatar University College of Pharmacy.

We thank the MUPS (Medication Use Process Study) Pharmacist Facilitator Group for their contributions in making this survey possible, in particular Dr Yassin Mohd Ahmed Abdulla, Mr Raed Hassan Abuafifeh, Dr Mohamad Ibrahim Ahmed, Ms Rana Hamad, Dr Khalid Al Hams, Ms Yolande Hanssens, Dr Mahmoud el Mahmoud, Mr Abou Baker
Mekoth, Dr Ibrahim Mohamadi, Ms Banan Mukhalalati, Dr Noora Obaidan, Ms Elham Al Saga, Mr Ahmad Abed El Samad, Ms Maha Samaii, Mr Diaa Sawaftah, Dr Aisha Al Ansari, and Dr Michael Walsh.

\section{Disclosure}

The authors of this manuscript have no conflicts of interest to declare.

\section{References}

1. Hawthorne N, Anderson C. The global pharmacy workforce: a systematic review of the literature. Hum Resour Health. 2009;7:48.

2. Anderson C, Bates I, Beck D, et al. The WHO UNESCO FIP Pharmacy Education Taskforce. Hum Resour Health. 2009;7:45.

3. Saad L. Nurses Shine, Bankers Slump in Ethics Ratings. Annual Honesty and Ethics Poll Rates Nurses Best of 21 Professions. November 24, 2001. www.gallup.com/poll/112264/nurses-shine-while-bankers-slumpethics-ratings.aspx?version=print. Accessed July 222009.

4. American College of Clinical Pharmacy. Healthy people 2010: challenges, opportunities, and a call to action for America's pharmacists. Pharmacotherapy. 2004;24(9):1241-1294.

5. Law AV, Ray MD, Knapp KK, et al. Unmet needs in the medication use process: perceptions of physicians, pharmacists, and patients. $J \mathrm{Am}$ Pharm Assoc. 2003;43(3):394-402.

6. Qatar. 2010. http://en.wikipedia.org/wiki/Qatar. Accessed June 32010.

7. Kheir N, Zaidan M, Younes H, et al. Pharmacy education and practice in 13 Middle Eastern countries. Am J Pharm Educ. 2008;72(6):1-13.

8. SurveyMonkey. 2010. http://surveymonkey.com.Accessed Jun 32010.

9. Birnbaum MH. SurveyWiz and factorWiz: JavaScript Web pages that make HTML forms for research on the Internet. Behav Res Methods Instrum Comput. 2000;32(2):339-346.

10. Lefever $\mathrm{S}$, Dal M, Matthíasdóttir A. Online data collection in academic research: advantages and limitations. Br J Educ Technol. 2006; 38(4):574-582.

11. Lacaria K, Balen RM, Frighetto L, et al. Perceptions of the professional pharmacy services in a major Canadian hospital: a comparison of stakeholder groups. Longwoods Review. 2004;2:8-19.

12. Fink A. The Survey Kit. 1st ed. California: Sage Publications; 1995.

13. Jackson C, Furnham A. Designing and Analyzing Questionnaires and Surveys: a Manual for Health Professionals and Administrators. London, PA: Whurr Publishers; 2000.

14. Task Force on a Blueprint for Pharmacy. Blueprint for pharmacy: the vision for pharmacy. 2008. http://www.pharmacists.ca/content/ about_cpha/whats_happening/cpha_in_action/pdf/BlueprintVision.pdf. Accessed June 32010.

15. Maio V, Goldfarb NI, Hartmann CW. Pharmacists' job satisfaction: variation by practice setting. $P \& T$. 2004;29(3):184-190.

16. Mott DA, Doucette WR, Gaither CA, et al. Pharmacists' attitudes toward worklife: results from a national survey of pharmacists. J Am Pharm Assoc. 2004;44(3):326-336.

17. Salameh P, Hamdan I. Pharmacy manpower in Lebanon: an exploratory look at work-related satisfaction. Res Social Admin Pharm. 2007; 3(3):336-350.

18. Bond CA, Raehl CL. Pharmacists' assessment of dispensing errors: risk factors, practice sites, professional functions, and satisfaction. $J$ Pharmacother. 2001;21(5):614-626.

19. Gaither CA. Career commitment: a mediator of the effects of job stress on pharmacists' work-related attitudes. J Am Pharm Assoc. 1999; 39(3):353-361. 


\section{Appendix A}

Online study survey instrument

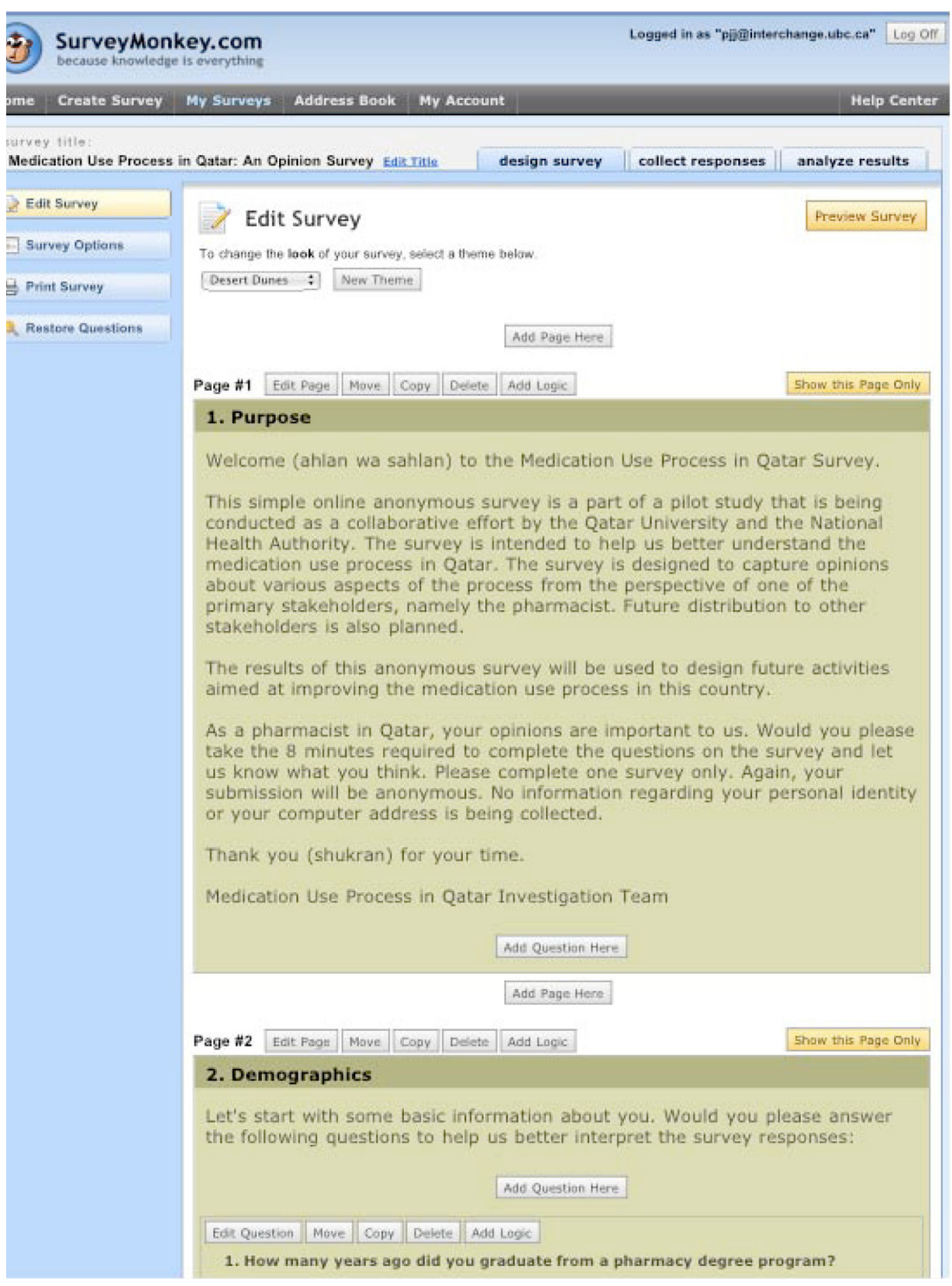




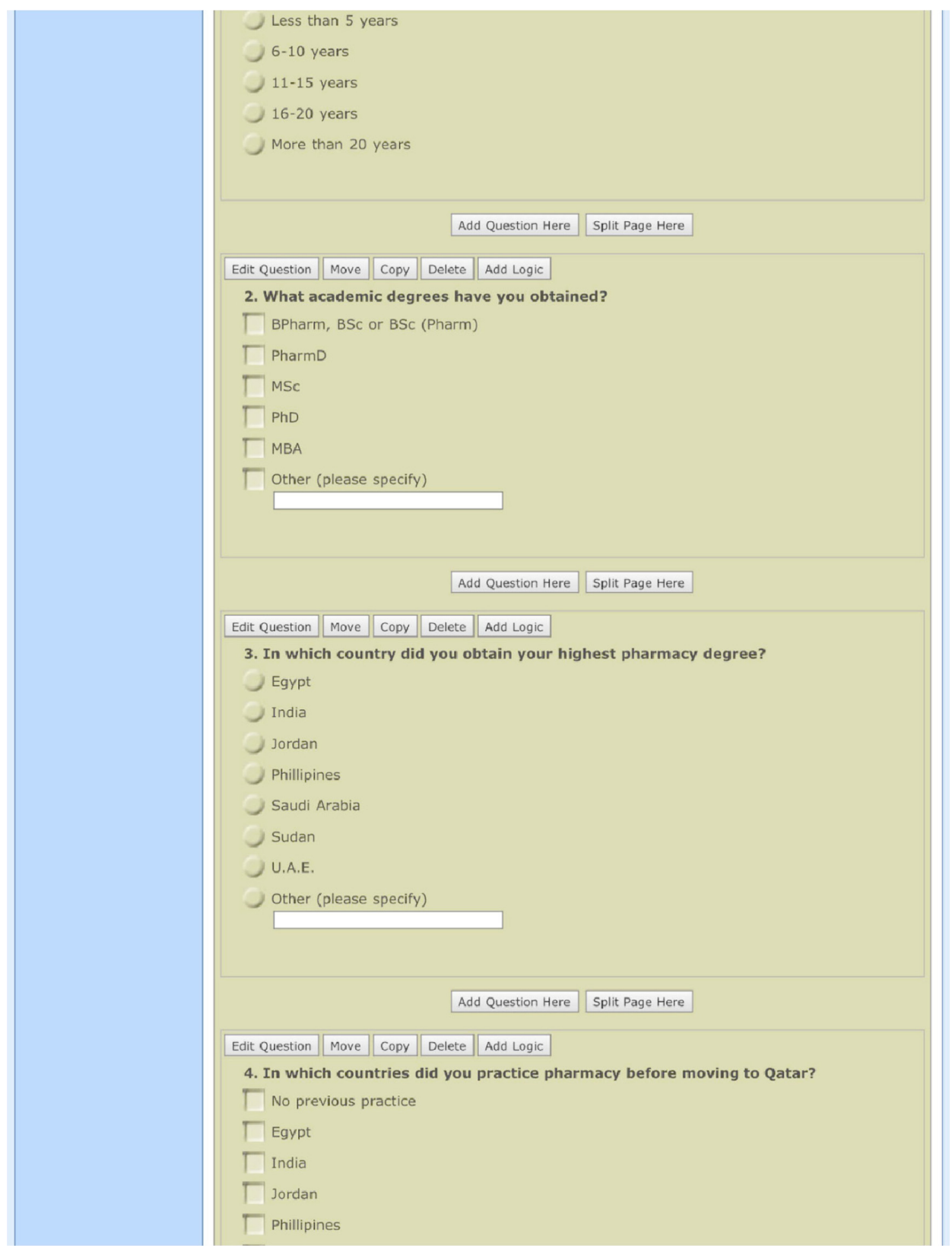



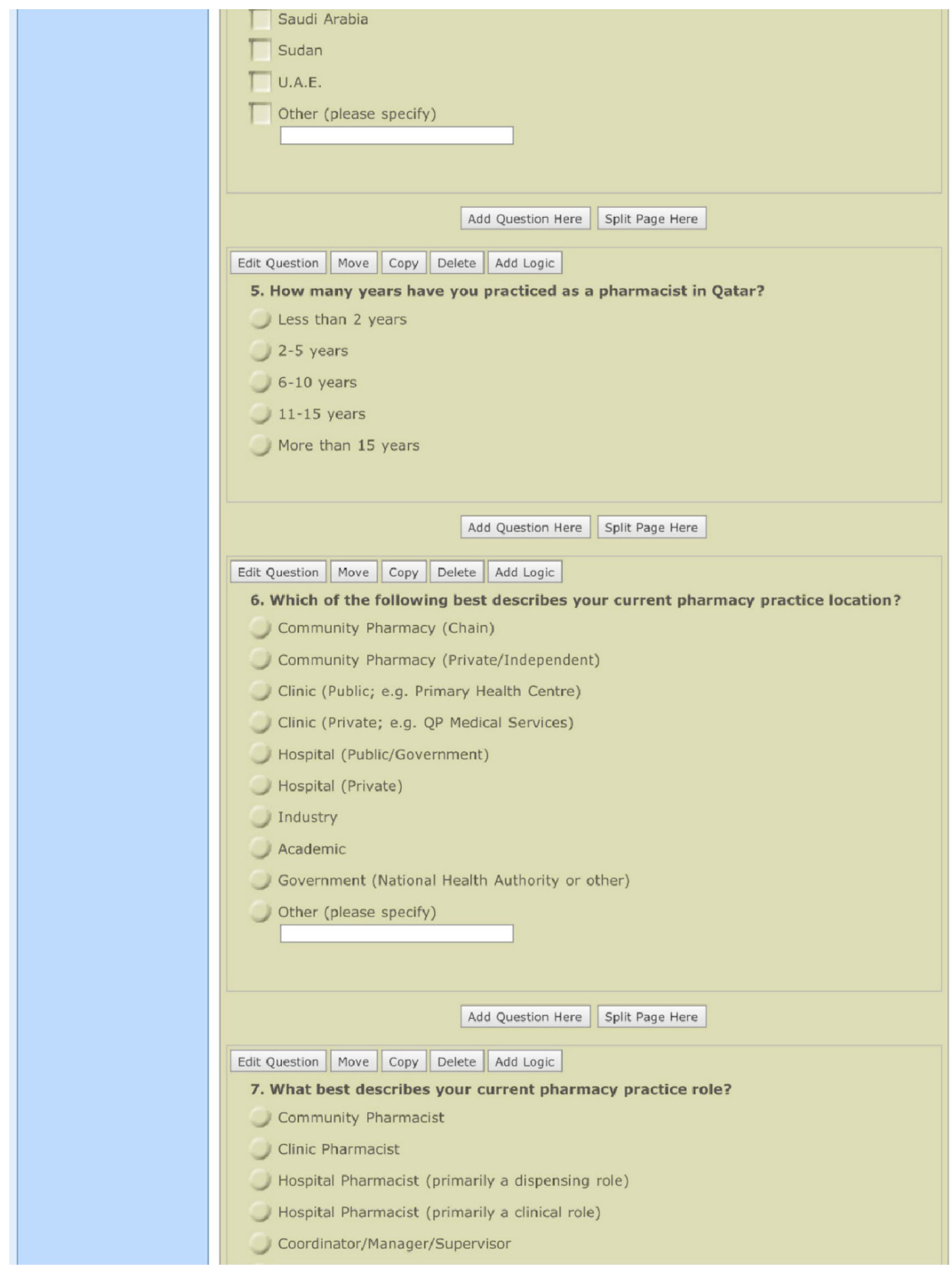

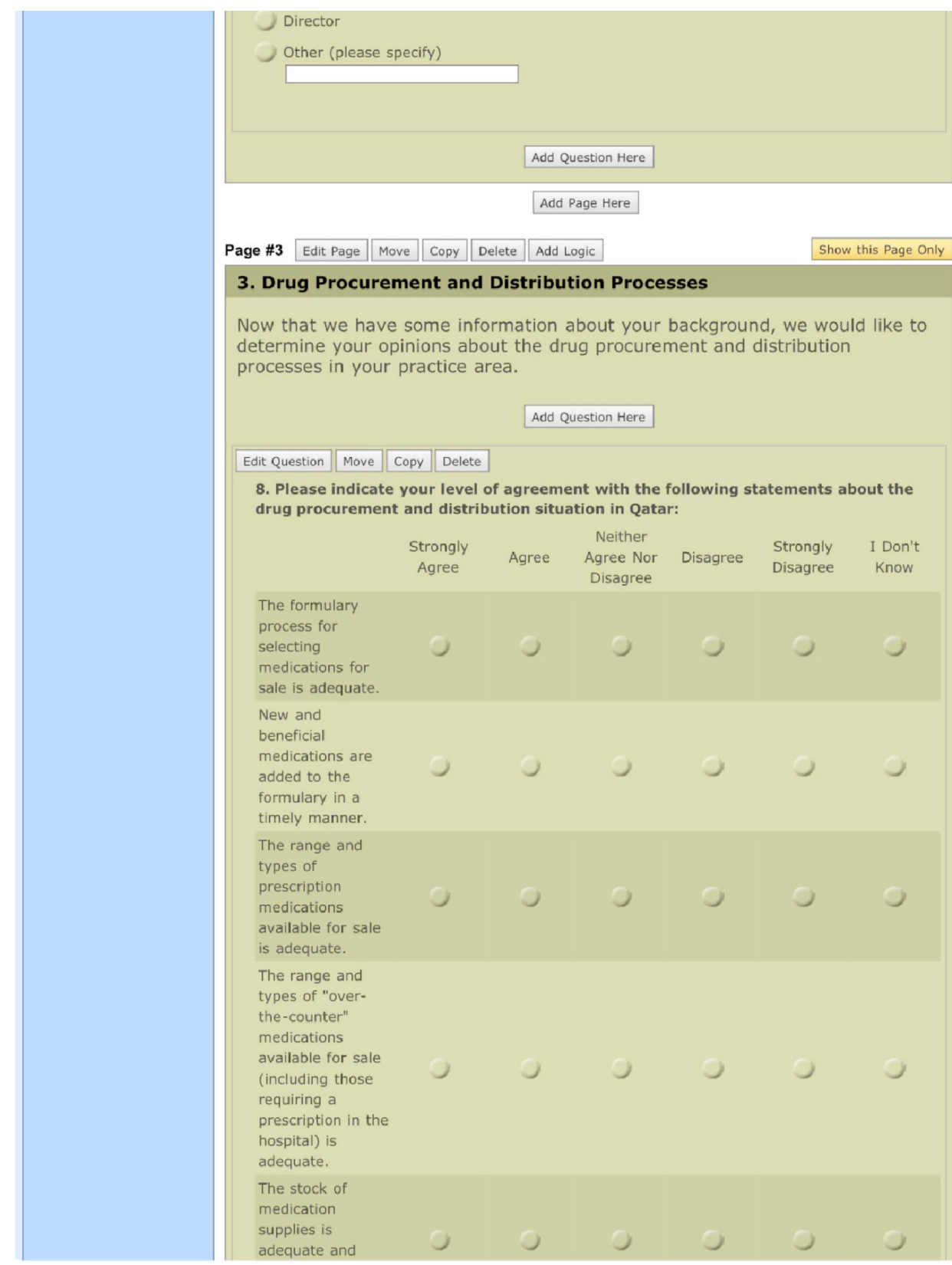

Page \#3 Edit Page Move Copy \begin{tabular}{|l|l|l|}
\hline Delete & Add Logic \\
\hline
\end{tabular}

Show this Page Only

3. Drug Procurement and Distribution Processes

Now that we have some information about your background, we would like to determine your opinions about the drug procurement and distribution processes in your practice area.

Add Question Here

Edit Question Mave Copy Delete

8. Please indicate your level of agreement with the following statements about the drug procurement and distribution situation in $\mathrm{Q}$ atar:

Strongly Agree $\begin{gathered}\text { Neither } \\ \text { Agree Nor Disagree } \\ \text { Disagree }\end{gathered}$
The formulary
process for
selecting
medications for
sale is adequate.
New and
beneficial
medications are
added to the
formulary in a
timely manner.
The range and
types of
prescription
medications
available for sale
is adequate.
The range and
types of "over-
the-counter"
medications
available for sale
(including those
requiring a
prescription in the
hospital) is
adequate.
The stock of
medication
supplies is
adequate and




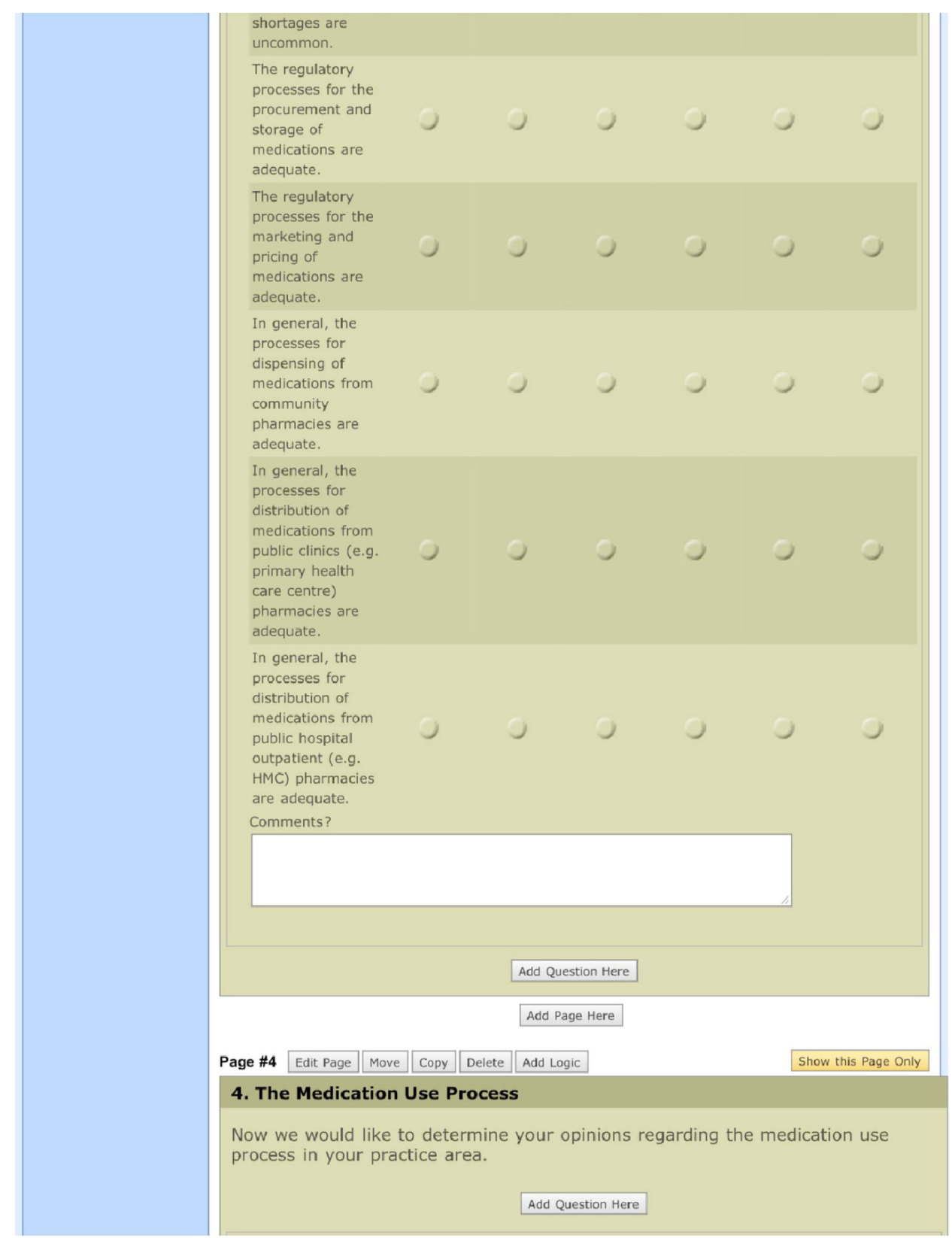




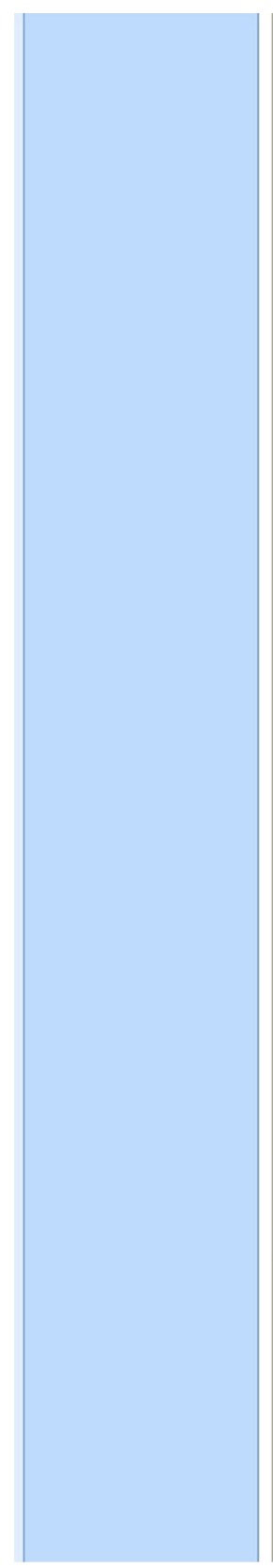

\begin{tabular}{|l|l|l|}
\hline Edit Question Mave Copy Delete \\
\hline
\end{tabular}

9. Please indicate your level of agreement with the following general statements

describing the current medication use situation in your practice area:

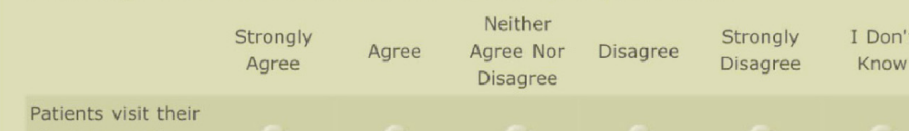

physician at the

right time.

The physician's

decision to use

medications is

appropriate.

Less than $5 \%$ of

prescriptions

received by

pharmacists

contain errors.

Patients get their

prescriptions filled

in a timely

manner.

Dispensing errors

are low.

Patients receive

adequate

medication

counseling.

Patients take (or

are administered)

their medications

as directed.

Patients are

monitored

appropriately.

Comments?

Add Question Here Split Page Here

Edit Question Mave Copy Delete

10. If you answered "Disagree" or "Strongly Disagree" to any of the statements in the question above, please identify who you believe would be the BEST possible

candidate(s)to resolve the particular unmet need for each statement that you disagreed with:

Physician Pharmacist Nurse Patient Management/Owner Government(NHA) Don't

Patients see

the physician

at the right

time. 


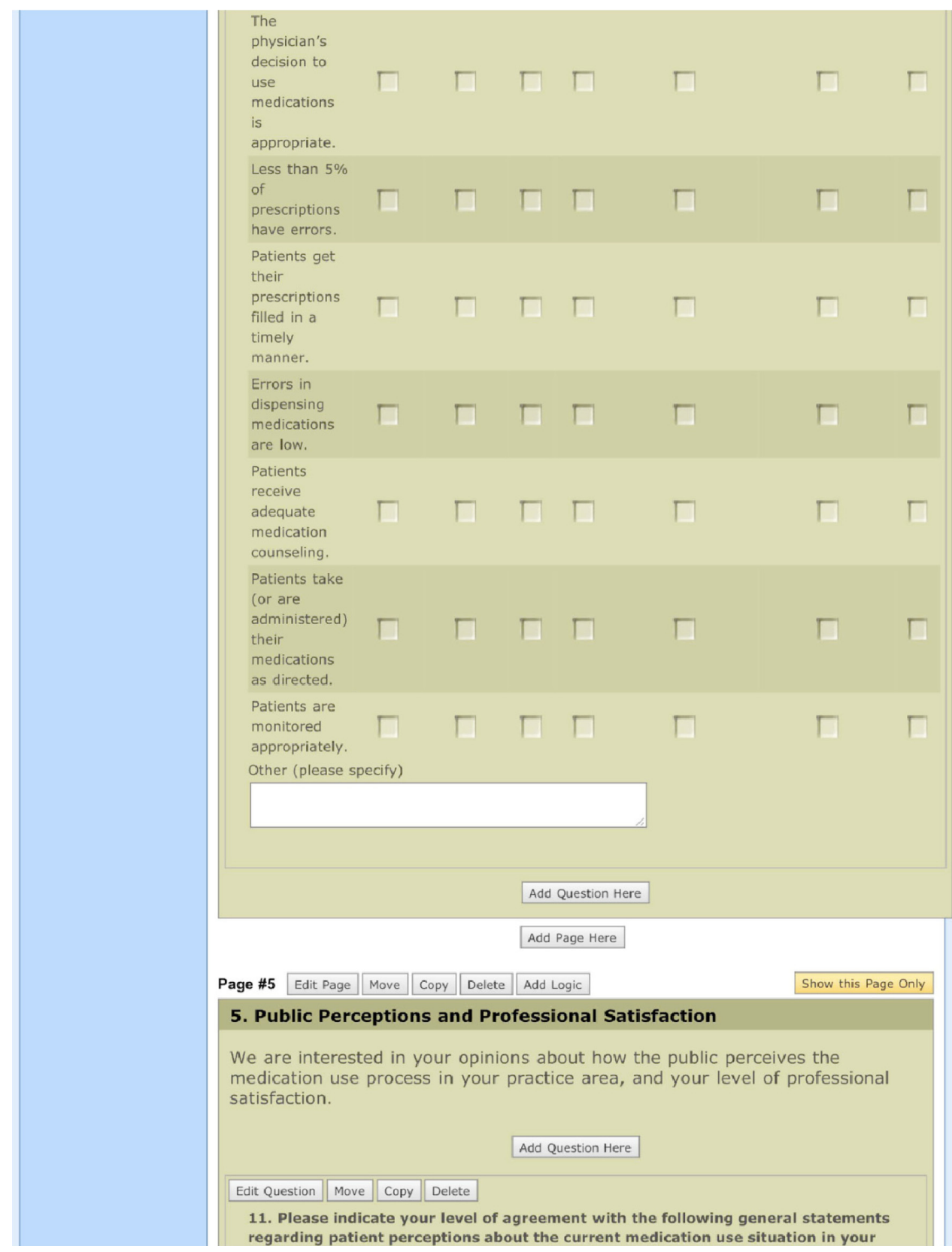




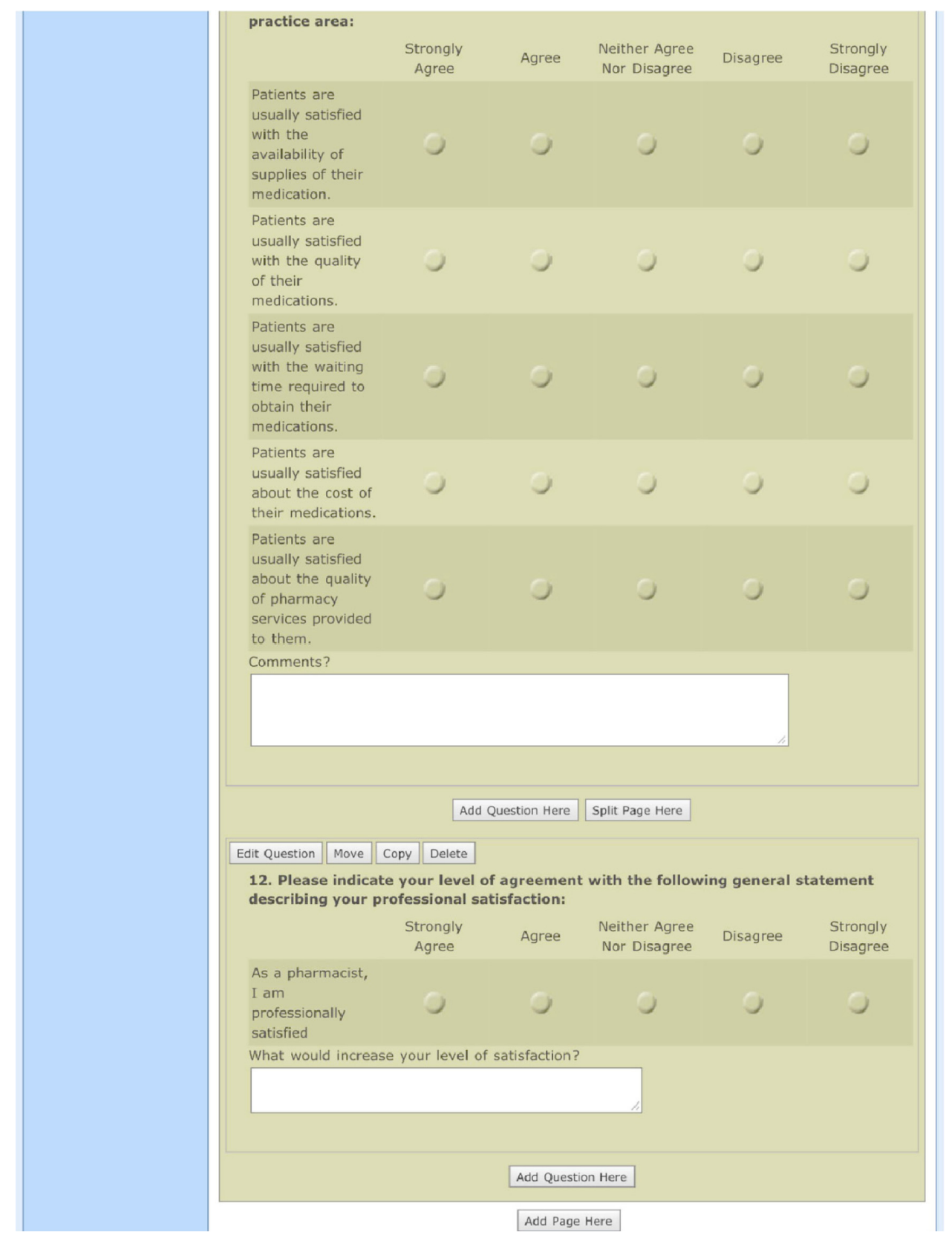




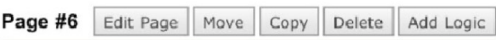

\section{Other Comments and Suggestions}

And finally, we are interested in your general opinions about the medication use process in Qatar and ways that you believe it could be improved.

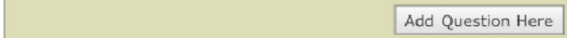

Edit Question Move Copy Delete

13. What aspects of the medication use process in Qatar do you consider to be best?

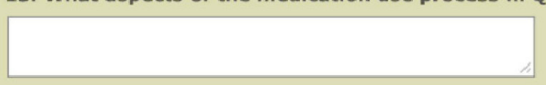

Add Question Here Split Page Here

Edit Question Move Copy Delete

14. What aspects of the medication use process in Qatar do you feel are in need of the greatest improvement?

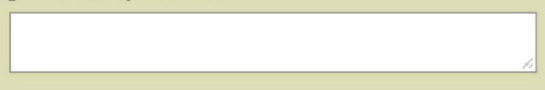

Add Question Here Split Page Here

Edit Question Move Copy Delete

15. What do you think can be done to further improve the medication use process in Qatar?

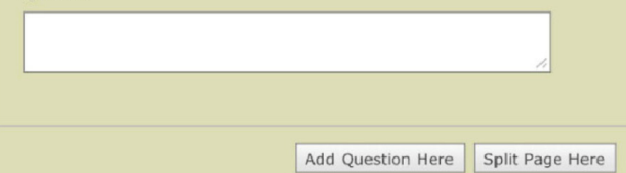

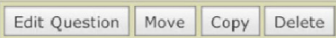

16. Do you have any other suggestions or comments regarding the medication use process, or anything else related to the delivery of health care in this country?

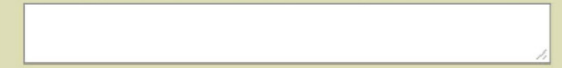

Add Question Here

Add Page Here

\begin{tabular}{l|l||l||l|l|l|l|l|l|}
\hline Page \#7 & Edit Page & Move & Copy & Delete & Add Logic \\
\hline
\end{tabular}

\section{Thank you (Shukran)}

Thank you very much for your anonymous contribution to this survey! Once the survey is closed and the responses analyzed, the results will be presented 


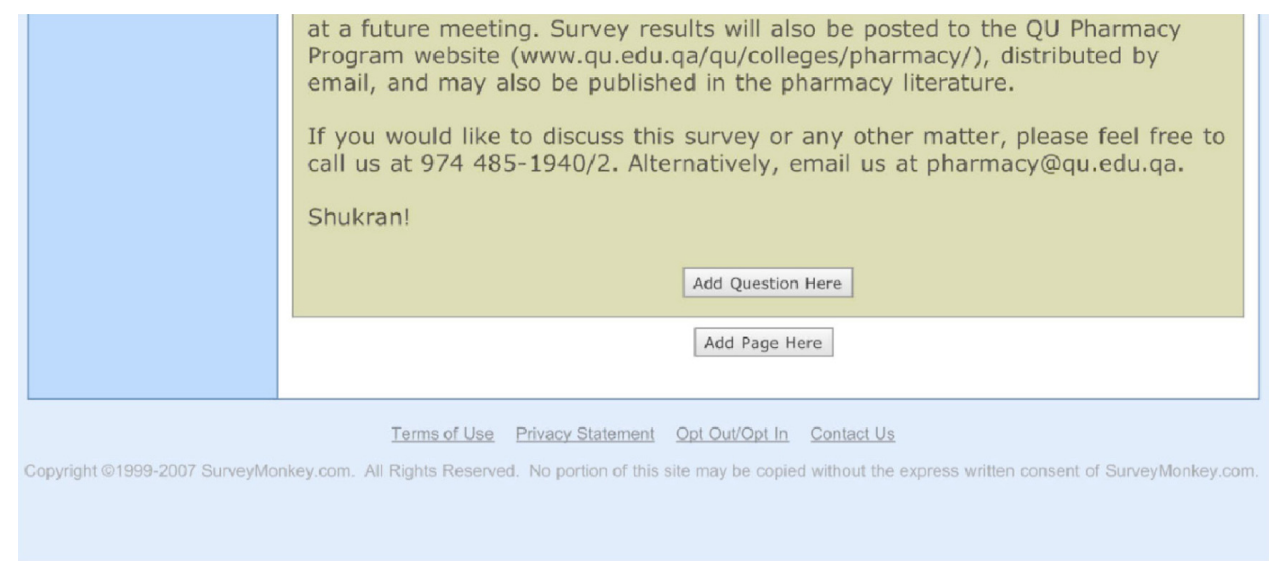

Journal of Healthcare Leadership

Dovepress

\section{Publish your work in this journal}

The Journal of Healthcare Leadership is an international, peer-reviewed, open access journal focusing on leadership for the health profession. The journal is committed to the rapid publication of research focusing on but not limited to: Healthcare policy and law; Theoretical and practical aspects healthcare delivery; Interactions between healthcare and society and evidence-based

practices; Interdisciplinary decision-making; Philosophical and ethical issues; Hazard management; Research and opinion for health leadership; Leadership assessment. The manuscript management system is completely online and includes a very quick and fair peer-review system. Visit http://www.dovepress. com/testimonials.php to read real quotes from published authors.

Submit your manuscript here: http://www.dovepress.com/journal-of-healthcare-leadership-journal 